\title{
Conhecimento e atitude das gestantes de alto risco sobre a transmissibilidade do vírus zika
}

\author{
Knowledge and attitude of women with high-risk pregnancy \\ about the Zika virus transmission
}

Clea Adas Saliba Garbin (https://orcid.org/0000-0001-5069-8812) ${ }^{1}$

Gabriela Peres Teruel (https://orcid.org/0000-0003-2686-589X) ${ }^{1}$

Tânia Adas Saliba (https://orcid.org/0000-0003-1327-2913) ${ }^{1}$

Suzely Adas Saliba Moimaz (https://orcid.org/0000-0002-4949-529X) ${ }^{1}$

Artênio José Ísper Garbin (https://orcid.org/0000-0002-7017-8942) ${ }^{1}$

${ }^{1}$ Programa de PósGraduação em Odontologia Preventiva e Social, Departamento de Odontologia Infantil e Social, Faculdade de Odontologia de Araçatuba, Universidade Estadual de

São Paulo. R. José Bonifácio 1193, Vila Mendonça. 16015-050 Araçatuba SP Brasil.cgarbin@foa.unesp.br

\begin{abstract}
Objective was to analyze the knowledge and attitude of high risk pregnant women about zika. This is a cross-sectional study, quantitative, with a sample of 201 high risk women who perform prenatal the Ambulatory Medical Specialties. A self-administered instrument, was applied after consultation with the doctor. Inclusion criteria were the presence of pregnant women on the day of the interview and their consent to participate. Exclusion criteria were those who did not agree to participate and were not performing prenatal care during the study period. For the data analysis we used chi square and fisher exact, in software Epi info 7.1 and Bioestat 5.0. Of the pregnant women, $76 \%$ believed that their neighborhood was likely to be infected by the virus and used measures to control mosquito proliferation, such as not leaving standing water $(n=154)$. In relation to knowledge, there was an association between Zika and microcephaly $(p \leq 0.0001)$ and the need for more information ( $p=0.0439)$. To prevent infection, $76 \%$ took no action, there was an association between the need for knowledge about the subject and the actions taken to combat the virus $(p=0.0049)$. We conclude that pregnant women's knowledge and attitude about zika is failed.
\end{abstract}

Key words Pregnant women, Public health, Zika virus
Resumo Objetivou analisar o conhecimento $e$ a atitude das gestantes de alto risco sobre a zika. Trata-se de um estudo transversal, quantitativo, com amostra de 201 gestantes de alto risco, que realizam pré-natal no Ambulatório Médico de Especialidades. Aplicou-se um instrumento auto administrado, aplicados após a consulta com o médico. Os critérios de inclusão utilizados foram a presença das gestantes no dia da entrevista e seu consentimento de participação. Os de exclusão as que não aceitaram participar e não estarem realizando o pré natal no período do estudo. Para análise de dados, utilizou-se qui-quadrado e exato de Fisher, nos softwares Epi info 7.1 e Bioestat 5.0. Das gestantes, 76\% acreditavam que, em seu bairro, é provável a infecção pelo vírus e utilizam medidas para controlar a proliferação do mosquito, como não deixar água parada $(n=154)$. Em relação ao conhecimento, houve associação entre a zika e a microcefalia ( $p \leq 0,0001)$ e o apontamento da necessidade de mais informações ( $p=$ 0,0439). Para impedir o contágio, 76\% não tomaram nenhuma atitude; houve, ainda, associação entre a necessidade de conhecimento sobre o assunto $e$ as ações realizadas no combate ao vírus ( $p=0,0049)$. Conclui-se que o conhecimento e a atitude das gestantes sobre a zika é falho.

Palavras-chave Gestantes, Saúde pública, Zika vírus 


\section{Introdução}

A evolução da gravidez ocorre, na maioria dos casos, sem intercorrências, provocando apenas alterações no organismo e no cotidiano materno, sejam elas físicas, hormonais, psíquicas ou de interação social, é um fenômeno fisiológico na vida da mulher ${ }^{1,2}$. A despeito disso, algumas mulheres podem apresentar complicações clínicas que aumentam os riscos para uma série de resultados adversos, tais como: pré-eclâmpsia, diabetes mellitus gestacional e trabalho de parto prematuro. Toda gestação traz algum risco para mãe e para o feto, porém espera-se que esta etapa transcorra sem intercorrências, uma vez que é um processo natural, apesar das mudanças ${ }^{3}$.

Já na gestação de alto risco, a mãe e/ou o feto apresentam problemas de saúde, algum agravo, com maiores probabilidades de evolução desfavorável da gravidez. Esse tipo de condição pode ocorrer por diversos fatores; um deles é a transmissão do vírus zika durante a gestação ${ }^{3,4}$.

A zika é uma doença viral transmitida pelo mosquito Aedes aegypti. A rápida propagação do vírus tem voltado a atenção das autoridades de saúde nacionais e internacionais para a execução de ações para diagnósticos e intervenção rápida em pacientes, principalmente gestantes, infectados pelo vírus. Essa preocupação existe, em especial, pela ligação do vírus com distúrbios neurológicos graves em recém-nascidos de mães expostas ao zika durante a gravidez ${ }^{5-7}$.

A doença, que migrou para o Brasil, possivelmente, em 2014, disseminou-se na região nordeste e pelas américas ${ }^{7,8}$. Resultados científicos contribuíram para aumentar a preocupação global com o vírus, já que, além da transmissão pela picada do mosquito contaminado, pela transmissão congênita/vertical, também há evidências que indicam o potencial significativo da transmissão pelo contato sexual ${ }^{8-10}$.

Com a proliferação do vírus, a Organização Mundial de Saúde lançou um alerta e decretou estado de emergência internacional, em função do aumento da incidência de microcefalia em zonas endêmicas ${ }^{8,11}$. Seis meses após o início do surto do vírus, houve um aumento incomum dos recém-nascidos com microcefalia no Brasil ${ }^{12}$, o que levou o Ministério de Saúde Pública Brasileiro a associar a má-formação com o vírus zika e a transmissão materna fetal ${ }^{10,12,13}$.

A microcefalia é uma complicação neurológica grave e irreversível, que pode ser causada pela infecção do vírus zika durante a gestação. Caracteriza-se por uma redução do perímetro cefálico, geralmente causada por um desenvolvimento inadequado e/ou pela destruição das células neurais. Pode ser detectada por ultrassons, tomografia, ou por medidas do perímetro cefálico ${ }^{14}$.

Em 2016, relatou-se um número alarmante de 7.438 casos suspeitos de microcefalia durante a $18^{a}$ semana epidemiológica de 2016 , realizada pelo Ministério da Saúde. Em meio a esses casos, 1.326 foram confirmados como infecção congênita. A maioria dos casos de microcefalia (5.706) tem sido relatada na região Nordeste $^{14}$.

Desta forma, no que diz respeito às consequências da síndrome da zika congênita, há que se observar que alterações cerebrais parecem ocorrer nos segundo e terceiro trimestres da gestação. Outras dismorfias, como acentuada protuberância óssea occipital, fontanelas fechadas ao nascer, excesso de pele e/ou dobras de pele no escalpo, além de hérnia umbilical, são frequentemente observadas em recém-nascidos de mães infectadas pelo vírus ${ }^{15,16}$.

As evidências atuais sobre a evolução natural da doença e sua patogenia, são fortes o suficiente para estabelecermos a relação causal entre a infecção pelo zika durante a gravidez e o aumento da frequência de abortos, natimortos e mortalidade precoce, além da microcefalia ${ }^{15-17}$. Nesse sentido, o vírus é um crescente problema de saúde pública em todo o mundo, principalmente devido ao seu potencial de dispersão e adaptabilidade a novos ambientes e hospedeiros, além da possibilidade de causar epidemias extensas, da suscetibilidade universal e dos grandes números de casos neurológicos graves ${ }^{18}$.

Em razão das dimensões desse problema, explicitadas acima, objetivou-se, neste estudo, analisar o conhecimento e a atitude das gestantes de alto risco, mais suscetíveis à doença em questão, sobre o vírus zika. Essa análise faz-se importante em vista da necessidade de que as gestantes ajam de modo a prevenir o vírus. Tal prevenção só pode ocorrer com base em um processo de conscientização sobre a doença e os seus riscos, que deve partir de uma noção a respeito das crenças já mobilizadas, pelas gestantes, sobre os pontos em discussão.

\section{Metodologia}

Trata-se de um estudo transversal, quantitativo, com amostra composta por 201 gestantes de alto risco, que realizam o pré-natal no Ambulatório Médico de Especialidades (AME). Todas possuem as mesmas condições socioeconômicas e 
têm acompanhamento pré-natal, também, nas Unidades Básicas de Saúde de seus bairros. Os AMEs são referência em saúde e estão em várias regiões do estado. São centros ambulatoriais de diagnóstico regulamentados pelo Sistema Único de Saúde, além de disporem de especialidades médicas, com ênfase nas necessidades da rede básica.

Este estudo foi realizado no AME de Araçatuba-SP, que atende aos Departamentos Regionais de Saúde (DRSII), englobando 28 municípios do noroeste paulista. A cada mês, são registradas, aproximadamente, oitenta gestantes de alto risco no AME de Araçatuba. Desse modo, para a composição da amostra, consideraram-se todas as gestantes de alto risco, em um período de 30 dias, que atendessem aos critérios de inclusão sua presença no dia da entrevista e seu consentimento para participar da pesquisa.

Os critérios de exclusão foram as gestantes que não aceitaram participar da pesquisa e não estarem realizando o pré natal no período do estudo.

Para a coleta de dados, aplicou-se um instrumento autoadministrado, em que foram abordados temas relacionados ao conhecimento e à atitude de gestantes de alto risco sobre o vírus zika, com base em questionários da Organização Mundial de Saúde. Os questionários com apenas questões de múltipla escolha eram aplicados no AME, após a consulta com o médico ginecologista, sem interferência de funcionários e em local isolado.

Para a análise de dados, foram utilizados a estatística descritiva, qui-quadrado e exato de Fisher, nos softwares Epi info 7.1 e Bioestat 5.0, considerando, para todas as análises, o nível de significância de 5\%. Foram considerados como perdas os questionários que não estavam preenchidos totalmente $(\mathrm{n}=32)$.

O presente estudo foi aprovado pelo Comitê de Ética em Pesquisa em Seres Humanos. Todos os ditames éticos foram seguidos. As gestantes com idade inferior a 18 anos assinaram o Termo de Assentimento e estavam sempre acompanhadas de um responsável.

\section{Resultados}

A amostra foi composta por 201 gestantes de alto risco, com idade média de 27,4 anos, tendo o ensino médio completo $(\mathrm{n}=121)$, ensino superior $(\mathrm{n}=14)$, ensino fundamental completo $(\mathrm{n}=21)$, e incompleto $(n=6)$. A maioria das mulheres que se propuseram a responder ao questionário estava no segundo trimestre gestacional $(n=91)$ (Tabela 1).

De acordo com as respostas das gestantes, $25 \%$ não sabiam que o mosquito transmissor do zika é o Aedes aegypti, o mesmo vetor da dengue (Tabela 2). Durante o período de estudo, 76\% responderam acreditar que, em seus bairros, seria provável a infecção pelo vírus zika. Essa mesma quantidade de entrevistadas relatou, ainda, que a responsabilidade de impedir o aumento do número de casos é de todos $(n=153)$ e que elas utilizam medidas para controlar a proliferação do mosquito, como: limpar todo recipiente que tiver água parada $(\mathrm{n}=154)$, manter o quintal limpo $(\mathrm{n}=139)$ e fazer uso de pesticidas $(\mathrm{n}=$ 131) (Tabela 2).

Quando questionadas sobre os principais sintomas do zika, os apontados com maior frequência foram dor de cabeça $(\mathrm{n}=102)$, febre $(\mathrm{n}=$ $93)$ e dor na articulação $(n=76)$. Entre as gestantes, 75 assinalaram não saber os sintomas (Tabela 2). Com relação à transmissão do vírus, a maioria das gestantes $(\mathrm{n}=108)$ não sabia que o zika pode ser transmitido por outros meios além do mosquito. Além disso, 79\% não estavam satisfeitas com as informações sobre a doença (Tabela 2).

No que diz respeito ao conhecimento sobre a questão abordada, houve associação entre o zika e a microcefalia $(p \leq 0,0001)$ e entre a falta de conhecimento e a necessidade de mais informações sobre o vírus $(\mathrm{p}=0,0439)$ (Tabela 3). Observou-se, ainda, que, quando questionadas sobre as ações realizadas para impedir o contágio do vírus zika durante a gestação, 76\% responderam que não tomaram nenhuma atitude. Houve, também, associação entre a necessidade de conhecimento sobre o assunto e as ações realizadas no combate ao vírus $(\mathrm{p}=0,0049)$ (Tabela 3$)$. Ainda em relação às informações sobre o vírus zika, a maioria $(\mathrm{n}=121)$ as obteve por meio das mídias sociais Facebook e Instagram.

\section{Discussão}

Como já destacado anteriormente, a preocupação com a infecção pelo zika vírus tem aumentado, em razão da epidemia na América Latina. A preocupação pela infecção pelo zika vírus vem aumentando, uma vez que causa defeitos cerebrais em recém-nascidos, como a microcefalia $^{19-21}$.

Nesse sentido, é válido destacar que a presença mais comum do mosquito é em áreas urbanas, 


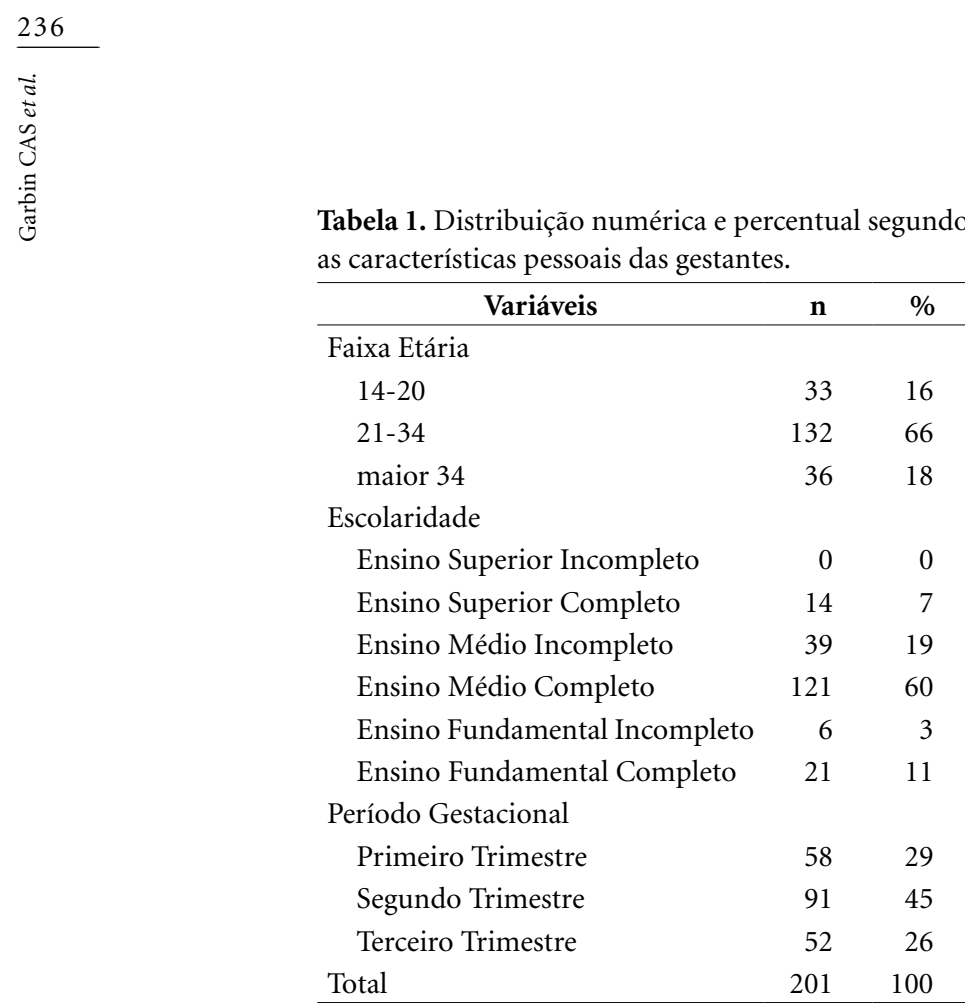

e a infestação é mais intensa no verão, em função da elevação da temperatura e da intensificação das chuvas ${ }^{22,23}$.

O mosquito tem causado muitas mortes pela dengue, o que mostra que o país já vem tendo problemas com o Aedes aegypti $i^{22}$. O vírus da dengue tem afetado gravemente a população brasileira há várias décadas, mas não houve resposta social, política ou sanitária adequada para lidar com o controle vetorial dessa infecção ${ }^{23}$. A situação de endemia dessas doenças revela a ineficácia de ações de prevenção e controle de vetores e ressalta os problemas de urbanização, uso do solo e desigualdade social, que exigem mudanças estruturais, com medidas eficazes no combate ao zika $^{23,24}$.

O zika é um microrganismo patogênico da família Flaviviridae, gênero Flavivirus. A doença causada pelo vírus é um grande problema de saúde pública, não somente pela infestação do mosquito Aedes aegypti, mas também pelo aumento populacional do Brasil e pela falta de políticas públicas de saneamento básico e de conscientização da população ${ }^{23,25}$. É necessária, assim, uma conscientização que não apenas esclareça tópicos de prevenção da infestação, mas que também apresente as consequências geradas pelas doenças transmitidas por esse mosquito ${ }^{25}$. Essa falta de informação pode ser ilustrada por um resultado
Tabela 2. Distribuição numérica segundo a percepção das gestantes sobre zika vírus e de acordo com a transmissibilidade do zika vírus.

\begin{tabular}{|c|c|}
\hline Variáveis & $\mathbf{n}$ \\
\hline \multicolumn{2}{|c|}{ Medidas de controle do mosquito } \\
\hline Fazer uso de pesticidas & 131 \\
\hline Deixar as luzes acesas & 19 \\
\hline Não deixar água parada & 154 \\
\hline Não ter animais em casa & 16 \\
\hline Trocar a roupa de cama & 29 \\
\hline Manter o quintal limpo & 139 \\
\hline Telas nas janelas & 25 \\
\hline Não sei & 18 \\
\hline \multicolumn{2}{|l|}{ Sintomas do Zika } \\
\hline Dor & 102 \\
\hline Erupção & 68 \\
\hline Diarreia & 73 \\
\hline Vômito & 57 \\
\hline Dor na articulação & 76 \\
\hline Febre & 93 \\
\hline Hemorragia & 25 \\
\hline Não sei & 75 \\
\hline \multicolumn{2}{|c|}{ Onde obteve informações sobre o vírus } \\
\hline Família & 14 \\
\hline Rádio & 6 \\
\hline Médico & 21 \\
\hline Redes Sociais & 10 \\
\hline Amigos & 5 \\
\hline Enfermeiro & 10 \\
\hline Televisão & 121 \\
\hline Posto de saúde & 55 \\
\hline Cirurgião Dentista & 1 \\
\hline \multicolumn{2}{|l|}{ Transmissor do Zika vírus } \\
\hline Aedes Aegypt & 149 \\
\hline Não sei & 52 \\
\hline \multicolumn{2}{|c|}{$\begin{array}{l}\text { Transmissão do vírus pode ocorrer no } \\
\text { bairro onde mora }\end{array}$} \\
\hline Sim & 153 \\
\hline Não & 48 \\
\hline Total & 201 \\
\hline
\end{tabular}

desta pesquisa, que aponta que 25\% das gestantes entrevistadas não sabiam que o vetor da zika é o mesmo da dengue.

Os sintomas mais frequentes da zika, citados pelas gestantes, foram dor de cabeça, febre e dor na articulação. Enquanto isso, 35,7\% gestantes assinalaram não saber os sintomas. Segundo Maguiña et al. ${ }^{26}$ e Cruz et al. ${ }^{27}$, o período de incubação do vírus varia de 3 a 12 dias, e $80 \%$ dos 
Tabela 3. Associação entre o conhecimento, atitude e informações das gestantes sobre o zika vírus.

\begin{tabular}{|c|c|c|c|c|}
\hline \multicolumn{3}{|c|}{ Conhecimento das gestantes de alto risco sobre o vírus zika } & \multirow{3}{*}{ Teste } & \multirow{3}{*}{ Valor de $\mathrm{p}$} \\
\hline \multirow{2}{*}{ Variáveis } & Não & Sim & & \\
\hline & $\mathbf{n}$ & $\mathbf{n}$ & & \\
\hline \multicolumn{5}{|c|}{ Você acha que há ligação entre Zika e Microcefalia? } \\
\hline Não & 38 & 15 & Qui-Quadrado & 0,0001 \\
\hline Sim & 40 & 108 & & \\
\hline \multicolumn{5}{|c|}{ Você gostaria de ter mais informações sobre o Zika? } \\
\hline Não & 12 & 8 & Exato de Fisher & 0,0439 \\
\hline Sim & 146 & 35 & & \\
\hline \multicolumn{5}{|c|}{ Tomou alguma atitude para evitar o contágio do Zika? } \\
\hline Não & 127 & 25 & Qui-Quadrado & 0,0049 \\
\hline Sim & 31 & 18 & & \\
\hline
\end{tabular}

${ }^{*}$ Nível de significância sendo 5\%.

afetados não apresentam sintomas, de modo que apenas 25\% têm febre leve, erupções cutâneas, conjuntivite (um sintoma típico de alta prevalência), dores de cabeça e nas articulações ${ }^{26,27}$.

Além da transmissão pelo Aedes aegypti, há evidências que indicam um potencial significativo para a ampliação global dos surtos de zika pela transmissão sexual, incluindo a presença prolongada do vírus no sêmen, por transfusão sanguínea e por meio da placenta ${ }^{10,18,26-32}$, como ocorre com o vírus HIV. No Brasil, os dados epidemiológicos mostram que, até junho de 2005, cerca de $83,7 \%$ das crianças menores de 13 anos que possuem o HIV se contaminaram pela transmissão vertical. Neste estudo, a maioria das gestantes não tinha conhecimento de que o vírus zika pode ser transmitido por outros meios além do mosquito ${ }^{33}$.

No que diz respeito ao conhecimento, houve significância na associação entre a zika e a microcefalia ( $\mathrm{p} \leq 0,0001)$. Sabe-se que o período intrauterino é uma fase crítica para o crescimento e desenvolvimento de órgãos e tecidos fetais, de maneira que injúrias sofridas nessa fase interferem no processo. Mulheres grávidas, quando infectadas pelo zika, podem transmiti-lo verticalmente, pela placenta ${ }^{12,18,34,35}$. A transmissão materna fetal do zika já foi demonstrada, pois, no Brasil, o vírus foi detectado no líquido amniótico de duas gestantes de bebês com microcefalia. Nesse sentido, em 11 de novembro de 2015, o Ministério da Saúde reconheceu a associação entre a epidemia de zika e o aumento dos casos de microcefalia caracterizada pela medida do crânio ou perímetro cefálico menor que menos dois
(-2), além de desvios-padrões abaixo da média específica para o sexo e idade gestacional ${ }^{12,18,34,35}$.

Dessa forma, é válido resgatar as palavras de Chan et al..$^{35}$, que colocam a expansão súbita da epidemia pelo vírus como uma das principais causas de distúrbios neuropsicomotores e incapacidades em uma geração de recém-nascidos acometidos por microcefalia secundária à infecção materna por vírus zika. Pode-se notar, então, que a situação estudada representa um grande fardo para as famílias envolvidas e alto encargo socioeconômico para os países afetados ${ }^{33,35}$.

Já sobre as informações do assunto em questão, é importante destacar que, de acordo com Gonçalves et al. ${ }^{36}$, há uma dificuldade em alterar o comportamento das pessoas no curto prazo, em nível individual ou coletivo, já que percepções e costumes estão arraigados no seu íntimo e são repassados, automaticamente, de geração a geração ${ }^{36}$. Daí a necessidade de investimento na conscientização como um processo, não apenas com atividades isoladas sobre a doença. Grande parte das pessoas envolvidas nas pesquisas, por exemplo, apresenta um bom nível de conhecimento sobre a doença, porém, algumas atitudes predatórias favoráveis ao aumento do número de casos persistem ${ }^{36}$.

Segundo Gonçalves Neto et al. ${ }^{28}$, o controle e a proliferação do Aedes aegypti acontece, essencialmente, no âmbito coletivo e exige um esforço de toda a sociedade. Assim, a população das áreas com ocorrência de transmissão precisa de informações que visem mudanças de atitudes, auxiliando na prevenção e no controle dessa doença. A esse respeito, observou-se, no presente estudo, 
a associação entre a falta de conhecimento sobre $o$ vírus e as ações realizadas para o combate do mosquito ( $\mathrm{p}=0,0049$ ), de modo que $76 \%$ das respondentes, como supracitado, não tomaram nenhuma atitude para impedir o contágio pelo vírus zika durante a gestação.

Logo, as ações da vigilância epidemiológica têm sido fundamentais para o monitoramento da evolução da epidemia do vírus zika no Brasil, bem como para a melhor compreensão das manifestações da doença e suas potenciais consequências, tanto em gestantes e seus bebês como em adultos ${ }^{37,38}$. Entretanto, há a necessidade de políticas públicas para melhorar as informações sobre o vírus, pois, como destacado por esta pesquisa, há associação entre a falta de conhecimento e a necessidade de mais informações sobre o zika vírus ( $p=0,0439)$, o que coloca as gestantes em risco.

Sobre as informações acerca do vírus zika, a maioria das gestantes $(n=121)$ as obtiveram por meio das mídias sociais facebook e instagram, corroborando com o estudo de Camilo et al..$^{39} \mathrm{e}$ Gonçalves Neto et al..$^{28}$, que observam que a mídia traz informações esclarecedoras e o incentivo à mobilização popular; a televisão e o rádio têm papel importante por serem meios de transmissão de fácil acesso ${ }^{28,39}$.

\section{Conclusão}

O conhecimento das gestantes sobre o vírus zika ainda é falho. É necessária, portanto, uma maior conscientização a respeito do assunto, especialmente por meio de mídias sociais, já que estas são, como demonstrou esta pesquisa, a plataforma mais utilizada, pelas gestantes, para o acesso às informações sobre o tema. É preciso, ainda, investir em políticas públicas que sensibilizem a comunidade e a orientem sobre a importância de ações coletivas para o combate às doenças propagadas pelo Aedes aegypti.

Essa necessidade foi corroborada por esta análise, tendo em vista o cenário apresentado pelas respostas aqui estudadas, de ausência das devidas precauções contra a transmissibilidade do vírus. Nesse sentido, é válido reforçar que a prevenção contra a doença e o acompanhamento das gestantes provavelmente infectadas pelo vírus zika são muito importantes, tendo em vista as potenciais consequências resultantes da infecção congênita, em especial a microcefalia e outras anomalias neurológicas.

\section{Colaboradores}

Os autores CAS Garbin, GP Teruel, TA Saliba, SAS Moimaz e AJI Garbin trabalharam igualmente na concepção e na redação do artigo. 


\section{Referências}

1. Anjos JCS, Pereira RR, Ferreira PRC, Mesquita TBP, Picanço Junior OM. Perfil epidemiológico das gestantes atendidas em um centro de referência em pré-natal de alto risco. Rev Para Med 2014; 28(2):23-33.

2. Brasil. Ministério da Saúde (MS). Atenção ao pré-natal de baixo risco. Brasília: MS; 2012.

3. Brasil. Ministério da Saúde (MS). Gestação de alto risco. Brasília: MS; 2000.

4. Moimaz SAS, Rós DT, Saliba TA, Garbin CAS. Aspectos da saúde geral e bucal de gestantes de alto risco: revisão da literatura. J Health Sci Inst 2017; 35(3):223230.

5. Saiz JC, Martín-Acebes MA, Bueno-Marí R, Salomón OD, Villamil-Jiménez LC, Heukelbach J, Alencar CH, Armstrong PK, Ortiga-Carvalho TM, Mendez-Otero R, Rosado-de-Castro PH, Pimentel-Coelho PM. Zika Virus: What have we learnt since the start of the recent epidemic. Front Microbiol 2017; 8:1554.

6. Haddow AD, Schuh AJ, Yasuda CY, Kasper MR, Heang V, Huy R, Guzman H, Tesh RB, Weaver SC. Genetic characterization of zika virus strains: geographic expansion of the Asian lineage. PLoS Negl Trop Dis 2012; 6:e1477.

7. Torres A. Enfermedad por virus de Zika y sus complicaciones neurológicas. Pediátr Panamá 2017; 46(2):41-45.

8. Nunes ML, Carlini OR, Marinowic D, Kalil Neto F, Fiori HH, Scotta MC, Zanella PLA, Soder RB, Costa JC. Microcephaly and Zika virus: a clinical and epidemiological analysis of the current outbreak in Brazil. J Pediatr 2016; 92(3):230-240.

9. Luz KG, Santos GIV, Vieira RM. Zika virus fever. Epidemiol Serv Saúde 2015; 24(4):785-788.

10. Possas C, Brasil P, Marzochi MCA, Tanuri A, Martins RM, Marques ETA, Bonaldo MC, Ferreira AGP, Oliveira RL, Nogueira RMR, Sequeira PC, Marzochi KBF, Homma A. Zika puzzle in Brazil: peculiar conditions of viral introduction and dissemination: a review. Mem Inst Oswaldo Cruz 2017; 112(5):319-327.

11. Gulland A. Zika virus is a global public health emergency, declares WHO. BMJ 2016; 352:i657.

12. Ventura CM, Maia M, Ventura BV, Linden VVD, Araújo EB, Ramos RC, Rocha MAW, Carvalho MDCG, Belfort Jr R, Ventura LO. Ophthalmological findings in infants with microcephaly and presumable intra-uterus Zika virus infection. Arq Bras Oftalmol 2016; 79(1):1-3.

13. Donalisio MR, Freitas ARR, Zuben APBV. Arboviruses emerging in Brazil: challenges for clinic and implications for public healt. Rev Saúde Pública 2017; 51:30.

14. Instituto Evandro Chagas (IEC). IEC Comprova relação do vírus zika com microcefalia e diagnostica os primeiros óbitos relacionados ao vírus [Internet]. 2015 [acessado 2016 Mar 13]. Disponível em: http://www. iec.gov.br/portal/iec-comprova-relacao-do-virus-zika-com-a-microcefalia-e-diagnostica-os-primeiros -obitos-relacionados-ao-virus/

15. Miranda-Filho DB, Martelli CMT, Ximenes RAA, Araújo TVB, Rocha MAW, Ramos RCF, Dhalia R, França RF, Marques Júnior ET, Rodrigues LC. Initial description of the presumed congenital Zika syndrome. Am J Public Health 2016; 106(4):598-600.
16. Oliveira Melo AS, Malinger G, Ximenes R, Szejnfeld PO, Alves Sampaio S, Bispo de Filippis AM. Zika virus intrauterine infection causes fetal brains abnormality and microcephaly: tip of the iceberg? Ultrasound Obstet Gynecol 2016; 47(1):6-7.

17. Calvet G, Aguiar RS, Melo AS, Sampaio SA, Filippis I, Fabri A, Araujo ESM, Sequeira PC, Mendonça MCL, Oliveira L, Tschoeke DA, Schrago CG, Thompson FL, Brasil P, Santos FB, Nogueira RMR, Tanuri A, Filippis AMBD. Detection and sequencing of Zika virus from amniotic fluid of fetuses with microcephaly in Brazil: a case study. Lancet Inf Dis 2016; 16(6):653-660.

18. Brasil. Ministério da Saúde (MS). Monitoramento dos casos de microcefalia no Brasil até a Semana Epidemiológica 47, 2015. Brasília: MS; 2015.

19. Regadas VC, Silva MC, Abud LG, Labadessa LMPL, Oliveira RGG, Miyake CH, Queiroz RM. Microcefalia causada por infecção congênita pelo Zika virus e detecção viral na urina materna durante a gestação. Rev Assoc Med Bras 2018; 64(1):11-14.

20. Williamson KE. Cuidado nos tempos de Zika: notas da pós-epidemia em Salvador (Bahia), Brasil. Interface (Botucatu) 2018; 22(66):685-696.

21. Carneiro R, Fleischer SR. "Yo no lo esperaba. Fue un susto": concebir, gestar y parir en tiempos de Zika en la visión de las mujeres de Recife, estado de Pernambuco, Brasil. Interface (Botucatu) 2018; 22(66):709719.

22. World Health Organization (WHO). Avaliação de bebés com microcefalia no contexto de vírus Zika [Internet]. 2016 [acessado 2016 Dez 17]. Disponível em: http://apps.who.int/iris/bitstream/handle/10665/204475/WHO_ZIKV_MOC_16.3_por.pdf?sequence $=8$

23. Leatte EP, Pont AMD. Epidemiologia da dengue e zika vírus na 13a Regional de Saúde do Paraná-Brasil. Rev Saúde Pesq 2017; 10(2):259-269.

24. Bueno FTC. Vigilância e resposta em saúde no plano regional: um estudo preliminar do caso da febre do Zika vírus. Cien Saude Colet 2017; 22(7):2305-2314.

25. Randow RMV, Silva JS, Brandão JFC, Oliveira IBC, Barbara JKO, Nascimento NG. Juntos no controle do aedes aegypti: educação em saúde. J Manag Prim Heal Care 2016; 7(1):137.

26. Maguiña C, Rodas EG. The Zika vírus: a literature review. Acta Med Peru 2016; 33(1):35-41.

27. Cruz RSBLC, Batista Filho M, Caminha MFC, Souza ES. Protocols on prenatal care for pregnant women with Zika infection and children with microcephaly: nutritional approach. Rev Bras Saúde Mater Infant 2016; 16(Supl. 1):S95-S102.

28. Gonçalves Neto VS, Monteiro SG, Gonçalves AG, Rebêlo JMM. Public knowledge and attitudes concerning dengue in the Municipality of São Luís, Maranhão, Brasil, 2004. Cad Saúde Pública 2006; 22(10):2191-2200.

29. Coelho FC, Durovni B, Saraceni V, Lemos C, Codeço CT, Camargo S, Carvalho LM, Bastos L, Arduini D, Villela DA, Armstrong M. Higher incidence of Zika in adult women than adult men in Rio de Janeiro suggests a significant contribution of sexual transmission from men to women. Int J Infect Dis 2016; 51:128-132. 
30. Calvet G, Aguiar RS, Melo ASO, Sampaio SA, Filippis I, Fabri A, Araujo ESM, Sequeira PC, Mendonça MCL, Oliveira L, Tschoeke DA, Schrago CG, Thompson FL, Brasil P, Santos FB, Nogueira RMR, Tanuri A, Filippis AMB. Detection and sequencing of Zika virus from amniotic fluid of fetuses with microcephaly in Brazil: a case study. Lancet Infect Dis 2016; 16(6):653-660.

31. Nicastri E, Castilletti C, Liuzzi G, Iannetta M, Capobianchi MR, Ippolito G. Persistent detection of Zika virus RNA in semen for six months after symptom onset in a traveller returning from Haiti to Italy, February 2016. Euro Surveill 2016; 21:32.

32. Mansuy JM, Dutertre M, Mengelle C, Fourcade C, Marchou B, Delobel P, Izopet J, Martin-Blondelet G. Zika virus: high infectious viral load in semen, a new sexually transmitted pathogen. Lancet Infect Dis 2016; 16(4):405.

33. Sá FE, Andrade MMG, Nogueira EMC, Lopes JSM, Silva APEP, Assis AMV. Produção de sentidos parentais no cuidado de crianças com microcefalia por vírus zika. Rev Bras Promoç Saúde 2017; 30(4):1-10.

34. Albuquerque MFPM, Souza WV, Araújo TVB, Braga MC, Miranda-Filho DB, Ximenes RAA, Brito CAA, Melo Filho DA, Valongueiro S, Melo APL, BrandãoFilho SP, Martell CMT. Epidemia de microcefalia e vírus Zika: a construção do conhecimento em epidemiologia. Cad Saúde Pública 2018; 34(10):e00069018.

35. Chan JFW, Choi GKY, Yip CCY, Cheng VCC, Yuen K-Y. Zika fever and congenital Zika syndrome: an unexpected emerging arboviral disease. J Infect 2016; 72(5):507-524.

36. Gonçalves RP, Lima EC, Lima JWO, Silva MGC, Caprara A. Contribuições recentes sobre conhecimentos, atitudes e práticas da população brasileira acerca da dengue. Saude Soc 2015; 24(2):578-593.

37. Garbin CAS, Garbin AJI, Moimaz SAS, Rocha NB. A transmissão vertical do HIV na percepção de mulheres brasileiras. Rev Odontol Araçatuba 2012; 33(1):4145.

38. Garcia LP, Duarte E. Evidências da vigilância epidemiológica para o avanço do conhecimento sobre a epidemia do vírus Zika. Epidemiol Serv Saúde 2016; 25(4):679-481.

39. Camilo EL, Santos GMMD, Valencoela LP, Barbosa JAS. A educação física no combate a dengue: Acadêmicos em foco. Rev Magsul 2016; 1(1):17-30.

Artigo apresentado em 02/02/2018

Aprovado em 15/04/2019

Versão final apresentada em 17/04/2019

Editores chefes: Romeu Gomes, Antônio Augusto Moura da Silva 